\title{
Fruit and vegetable intake among Emirati adolescents: a mixed methods study
}

Nora Makansi, ${ }^{1}$ Paul Allison, ${ }^{2}$ Manal Awad ${ }^{3}$ and Christophe Bedos ${ }^{2}$

${ }^{1}$ Center for Research on Children and Families, McGill University, Montreal, Quebec, Canada (Correspondence to: Nora Makansi: nora.makansi@ mail.mcgill.ca). ${ }^{2}$ Faculty of Dentistry, McGill University, Montreal, Quebec, Canada. ${ }^{3}$ Department of Preventative and Restorative Dentistry, College of Dental Medicine, University of Sharjah, Sharjah, United Arab Emirates.

\begin{abstract}
Background: Interventions to promote healthy eating in adolescents are needed in the United Arab Emirates. To design effective interventions, adolescent eating behaviours need to be understood.

Aims: This study aimed to describe eating behaviours of adolescents in Dubai and the factors associated with fruit and vegetable intake.

Methods: This was a sequential explanatory study using a mixed methods approach. Ten of the 34 Arabic high schools in Dubai were randomly selected and students in grades 10-12 were included. Data were collected on self-reported fruit and vegetables intake, eating behaviours, food availability and sociodemographic variables. In the qualitative phase, 14 students were interviewed about their eating behaviour.

Results: A total of 620 students were included: $57 \%$ were boys and most reported medium/high family affluence. Only $28 \%$ of the participants met the recommended daily fruit and vegetable intake, with significantly more males than females meeting it $(\mathrm{P}<0.01)$. Lunch was the most frequently eaten meal, breakfast was frequently skipped, and there were high levels of fast food and soft drink consumption. Adequate fruit and vegetable intake was positively associated with increased lunch frequency, being male, parental support for healthy eating, and positive perception of family meals.

Conclusions: There are significant differences in eating habits between Emirati male and female adolescents. Lunch, as the main family meal, faces threats because of modern working hours. The gender-specific social context may require targeted interventions to achieve optimal outcomes in each group.

Keywords: Eating behaviour; adolescent; diet, obesity, United Arab Emirates

Citation: Makansi N; Allison P; Awad M; Bedos C. Fruit and vegetable intake among Emirati adolescents: a mixed methods study. East Mediterr Health J. 2018;24(7):653-663. https://doi.org/10.26719/2018.24.7.653

Received: 08/08/16; accepted: 12/07/17

Copyright ( ) World Health Organization (WHO) 2018. Some rights reserved. This work is available under the CC BY-NC-SA 3.0 IGO license (https:// creativecommons.org/licenses/by-nc-sa/3.o/igo).
\end{abstract}

\section{Introduction}

Eating behaviours of adolescents in the Middle East have evolved and now tend to resemble those reported in Western Europe and North America, especially in terms of snacking and fast food consumption $(1,2)$. Such behaviours have been associated with several diseases, including obesity and type 2 diabetes $(3,4)$. This phenomenon is particularly evident in Gulf countries, such as the United Arab Emirates (UAE) (5), where oil wealth relative to the small population size has prompted rapid socioenvironmental and nutritional shifts.

In the UAE, significant associations were found in adolescent females between obesity, missing breakfast and fast food consumption (6). Combined figures of overweight and obesity in the Gulf region are now as high as $42.2 \%$ in Kuwaiti adolescent males and $42.4 \%$ among Bahraini adolescent females (7). The European Society of Cardiology warns that the Gulf region is facing an epidemic of cardiovascular diseases, describing the situation as a "time bomb set to explode in 10-15 years" (8).
Increased intake of fruits and vegetables has a protective effect against chronic diseases (9). Interventions to promote healthy eating among adolescents are particularly relevant in countries like the UAE. In order to design targeted interventions, we need to understand these behaviours within their socioenvironmental context. Therefore, the aim of this study was: 1) to describe and understand the eating behaviours of Emirati adolescents in the UAE, and 2) to explore behavioural and contextual factors associated with their fruit and vegetable intake. Such findings can inform future interventions and may also be transferable to neighbouring Gulf countries that share similar social, economic and environmental characteristics.

\section{Methods}

\section{Study design}

A sequential explanatory study using a mixed methods approach was selected for its potential to capture the multidimensional nature and complexity of eating behaviour. Quantitative data were first collected followed by qualitative data. 


\section{Study population and sampling}

At the time of recruitment for the study, there were 24 public and 48 private high schools in Dubai. The majority of Emirati students (64\%) attend public high schools (10). The study was carried out in Arabic, hence, our sampling frame included Arabic high schools only. A total of 34 high schools (24 public and 10 private) were retained in the sampling frame. We randomly selected 4 out of 10 male public schools, 4 out of 14 female public schools, and 2 out of 10 private schools. Two of the public schools we initially contacted declined because of "lack of time", and another 2 were randomly selected.

\section{Quantitative phase}

\section{Sample size}

Based on previous research $(11,12)$, it was estimated that the proportion of adolescents who meet the daily recommended intake of fruits and vegetables was 32\%. Using the appropriate formula for proportions (13), and assuming a design effect of 2 (given the cluster design of the study), a sample size of 668 was calculated. The final sample size was 700. Classes were recruited within the schools based on the availabilities in the academic schedules. All students in a selected class were invited to participate.

\section{Data collection}

The survey was administered during school hours to students who had returned the signed parental consent forms and agreed to participate. We used the validated EAT (Eating Among Teens) survey (14). We also included a standard set of questions to assess fruit and vegetable intake based on the YRBS (Youth Risk Behavior Surveillance) survey (15). The tool was translated from English into Arabic using a multistage process of back translation (translation, synthesis, back translation, expert review and pretesting) and was adapted to cultural values of the UAE (16). We pilot-tested the translated questionnaire on a convenience sample of grade 10 students in a girls' public school $(\mathrm{n}=29)$. One of the authors (NM) was present throughout the session to answer and clarify any questions and collect the written feedback. Based on the pilot survey, and after consultation with the research team members and a professor from the faculty of dietetic and human nutrition at McGill University, the final modifications of the survey included the omission of items measuring self-efficacy. This was done to reduce the length of the survey and to focus on practical findings that can be directly addressed by an intervention.

\section{Questionnaire items}

We assessed self-reported intake of fruit and vegetables, meal frequency, snacking patterns, fast food intake, and soft drink consumption. Sociodemographic variables included: age, sex, grade and family affluence (based on number of cars owned by the family, family holidays in the past year and family computers, and having own bedroom). Socioenvironmental factors included: frequency of family meals, parental presence at meals, priority of family meals, parental support for healthy eating, and atmosphere of family meals. Finally, we assessed the availability of fruit and vegetables, and some common unhealthy snacks (crisps, chocolate, candy and soft drinks) at home and at school. Details of the variables are given in the supplemental table (available on line).

\section{Data analysis}

AnalysiswasperformedusingSPSS, version20.Descriptive statistics were used to describe the demographic characteristics of the sample. The association between eating behaviours and sex was explored using the chisquared test. A single level multivariate analysis was done using the generalized linear mixed model (17). The dependent variable was dichotomized as: $0=$ not meeting the recommended daily intake of fruit and vegetables and $1=$ meeting the recommended daily intake (18). The cut-off score for adequate fruit and vegetable intake combined (in relation to recommended daily intake) was $\geq 5$ portions per day.

\section{Qualitative phase}

\section{Sample selection}

Since our goal was to inform future nutritional interventions for this target population, the sampling frame included students who did not meet the recommended daily intake of fruit and/or vegetables. We used stratified purposeful sampling based on sex and frequency of reported intake (students reporting zero intake of fruit and/or vegetables and students reporting less than the recommended intake). Participants were then purposefully selected from these strata. The rationale for stratifying was to capture various profiles within the sampling frame.

\section{Sample size}

The sample size was determined during data collection based on reaching thematic saturation. The decision to stop at 14 interviews followed a sense of saturation on main themes of interest, as well as the time limitation as students were approaching the examination period.

\section{Data collection}

A semi-structured interview guide was developed from the findings of the quantitative phase. The goal was to give context to and further our understanding of the quantitative findings (19). All students invited agreed to participate. The first author (NM) conducted all interviews, accompanied by a research assistant. Interviews lasted about 25-30 minutes and were audio recorded for transcription and analysis.

\section{Data analysis}

We analysed interview data using qualitative content analysis with an unconstrained deductive coding approach (20). We developed a list of categories and preliminary codes based on the survey items, such as "meal skipping" and "parental influence". We also coded emerging themes such as "social norms" and "parental control". NM and the research assistant independently coded two interview transcripts for cross-comparison. Results were regularly discussed with the research team. 


\section{Ethical considerations}

Ethical approval was obtained from the Research Ethics Committee at the University of Sharjah, UAE, and from the Institutional Review Board at McGill University in Montreal, Canada. Permission to access schools was obtained from the Knowledge and Human Development Authority of Dubai.

\section{Results}

Out of the 700 questionnaires handed out, 80 were completed by non-Emirati students and hence were excluded from the analysis. Table 1 shows the demographic characteristics of the overall sample $(n=620)$. Most participants reported high (47.1\%) to medium (39.7\%) family affluence. About half of them (48.9\%) reported that neither parent had attended college/university.

In the qualitative phase, the sample consisted of seven females and seven males. At the time of the interviews, nine participants were in grade 12 and 5 were in grade 11. Seven participants reported high family affluence and nine indicated that neither of their parents had attended college/university. The sections below report the integrated quantitative and qualitative findings.

\section{Eating behaviours}

Less than a third of the participants met the recommendations for intake of fruit and vegetables combined, however, males were significantly more

\begin{tabular}{|c|c|c|}
\hline \multicolumn{3}{|c|}{$\begin{array}{l}\text { Table } 1 \text { Sociodemographic characteristics of high-school } \\
\text { students }(\mathrm{n}=\mathbf{6 2 0})\end{array}$} \\
\hline Variable & No. & $\%$ \\
\hline \multicolumn{3}{|l|}{ Sex } \\
\hline Male & 351 & 56.6 \\
\hline Female & 269 & 43.4 \\
\hline \multicolumn{3}{|l|}{ Age (years) } \\
\hline$\leq 15$ & 104 & 16.8 \\
\hline 16 & 218 & 35.2 \\
\hline 17 & 177 & 28.5 \\
\hline$\geq 18$ & 121 & 19.5 \\
\hline \multicolumn{3}{|l|}{ Grade } \\
\hline 10 & 164 & 26.5 \\
\hline 11 & 218 & 35.2 \\
\hline 12 & 238 & 38.4 \\
\hline \multicolumn{3}{|l|}{ Family affluence scale } \\
\hline Low & 81 & 13.1 \\
\hline Medium & 246 & 39.7 \\
\hline High & 292 & 47.1 \\
\hline \multicolumn{3}{|l|}{ Parental education } \\
\hline $\begin{array}{l}\text { Neither attended college/ } \\
\text { university }\end{array}$ & 303 & 48.9 \\
\hline $\begin{array}{l}\text { At least one parent attended } \\
\text { college/university }\end{array}$ & 236 & 38.1 \\
\hline Don't know & 81 & 13.1 \\
\hline
\end{tabular}

likely than females to meet the recommendations $(33.2 \%$ males versus $21.3 \%$ females, $P<0.01$ ) (Table 2). Breakfast was the most frequently skipped meal with a significant difference between girls and boys $(P<0.001)$. On school mornings, participants explained that they lack appetite. On weekends, however, most participants eat a breakfast meal because they are "more relaxed" and "not pressed for time".

During school hours, food choices were limited. The school canteen sold prepackaged croissant, za'tar bread, crisps, chocolate, juices and occasional cooked foods like pasta or French fries. The schools in our sample had no assigned dining areas and students typically ate in the schoolyard. Most participants said they would not bring food from home explaining, as two girls said; "no one does that!" and "(Only) girls who are on a diet."

When probed on school food choices, participants criticized the quality and presentation of food. Some suggested adding traditional hot meals while others described the available selection as "boring", "Cold and not appetizing".

Participants always ate "lunch" at home after returning from school. All participants described lunch as the most significant meal of the day, hence confirming the quantitative results (Table 2). This significance stemmed from factors including location, timing, quality and social context of the lunch meal.

Lunch consisted of traditional meat or vegetable stews with rice as a staple side dish. Salads were often served as well. In terms of context, lunch was the time for family gathering. However, some participants explained that it had become difficult for some family members to attend lunch because of longer working hours; lunch would therefore be set up at a certain time and family members ate at different times upon their arrival from school or work.

More students skipped dinner than lunch (Table 2). Like breakfast there was a significant difference between boys and girls $(P<0.01)$. Participants described dinner as a "light" meal eaten later in the evening. They also appeared to have more control over food choices in the evening citing choices like fast food meals, instant noodles and sandwiches.

\section{Socioenvironmental factors}

Table 3 shows the prevalence of family meals, parental presence at meals, and availability of fruit and vegetables at home. Participants reported high availability of fruit and vegetables at home only but at school they were rarely available; on the other hand, potato crisps, chocolate and candy were reportedly "always" available at school.

More than a third of the students recognized time barriers as a threat to family meals (Table 4). This finding was supported during the interviews as students described the conflict between long working hours and having lunch with the family. 


\begin{tabular}{|c|c|c|c|}
\hline Eating behaviour & $\begin{array}{c}\text { Males }(\mathrm{n}=351) \\
\text { No. }(\%)\end{array}$ & $\begin{array}{c}\text { Females }(n=269) \\
\text { No. }(\%)\end{array}$ & P-value ${ }^{\mathrm{a}}$ \\
\hline \multicolumn{4}{|l|}{ Meal frequency (past 7 days) } \\
\hline Brealffast (days) & & & $<0.001$ \\
\hline Never & $46(13.2)$ & $53(19.8)$ & \\
\hline $1-2$ & $67(19.2)$ & $75(28.0)$ & \\
\hline $3-4$ & $43(12.3)$ & $44(16.4)$ & \\
\hline $5-6$ & $37(10.6)$ & $21(7.8)$ & \\
\hline Daily & $156(44.7)$ & $75(28.0)$ & \\
\hline \multicolumn{4}{|l|}{ Lunch (days) } \\
\hline Never & $8(2.3)$ & $5(1.9)$ & \\
\hline $1-2$ & $22(6.3)$ & $21(7.8)$ & \\
\hline $3-4$ & $62(17.7)$ & $62(23.1)$ & \\
\hline $5-6$ & $43(12.3)$ & $40(14.9)$ & \\
\hline Daily & $216(61.5)$ & $140(52.2)$ & \\
\hline Dinner (days) & & & $<0.01$ \\
\hline Never & $15(4.3)$ & $6(2.2)$ & \\
\hline $1-2$ & $42(12.0)$ & $42(15.6)$ & \\
\hline $3-4$ & $45(12.8)$ & $66(24.5)$ & \\
\hline $5^{-6}$ & $71(20.2)$ & $43(16.0)$ & \\
\hline Daily & $178(50.7)$ & $112(41.6)$ & \\
\hline \multicolumn{4}{|c|}{ Frequency of foods/drinks consumed } \\
\hline \multicolumn{4}{|l|}{ Soft drinks intake (past 7 days) $)^{b}$} \\
\hline None & $57(16.4)$ & $51(19.0)$ & \\
\hline Less than once a day & $148(42.5)$ & $126(47.0)$ & \\
\hline At least once a day & $143(41.1)$ & $91(34.0)$ & \\
\hline \multicolumn{4}{|c|}{ Frequency of eating fast food (past 7 days) } \\
\hline Never & $79(22.6)$ & $50(18.6)$ & \\
\hline $1-2$ times & $175(50.1)$ & 137 (50.9) & \\
\hline$\geq 3$ times & $95(27.2)$ & $82(30.5)$ & \\
\hline \multicolumn{4}{|l|}{ Snacking frequency (previous day) } \\
\hline Never & $77(22.1)$ & $53(19.7)$ & \\
\hline Once & $128(36.7)$ & $89(33.1)$ & \\
\hline $2-3$ times & $101(28.9)$ & $86(32.0)$ & \\
\hline$\geq 4$ times & $43(12.3)$ & $41(15.2)$ & \\
\hline Fruit and $100 \%$ fruit juice intake & & & $<0.01$ \\
\hline$\geq 2$ portions per day & $132(37.7)$ & $70(26.1)$ & \\
\hline Vegetable intakec & & & $<0.01$ \\
\hline$\geq 3$ portions per day & $111(31.8)$ & $56(20.9)$ & \\
\hline Fruit and vegetable intake & & & $<0.01$ \\
\hline$\geq 5$ portions per day & $116(33.2)$ & $57(21.3)$ & \\
\hline
\end{tabular}

${ }^{a}$ Chi-squared test.

${ }^{b}$ A can, bottle or glass.

'Green salad, potatoes (excluding French fries), carrots or other vegetables

\section{Factors associated with fruit and vegetable intake}

Table 5 shows the factors associated with meeting the recommended daily fruit and vegetable intake. Being male, eating frequent lunches, consuming soft drinks and snacking were significantly associated with meeting the recommendations for fruit and vegetable intake across the models. In the final adjusted model (model 3), parental support for healthy eating and family meal 


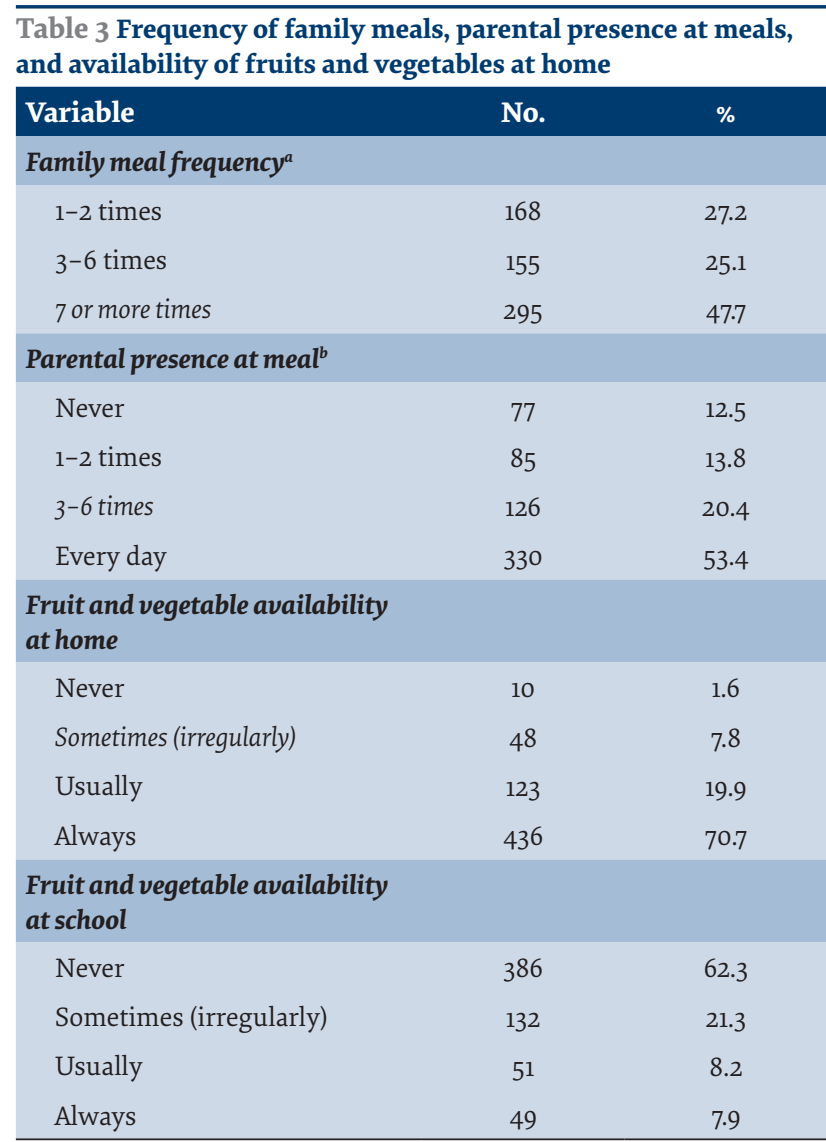

${ }^{a}$ Number of times in the past 7 days all or most of the family living in the house ate a meal together.

${ }^{b}$ Number of times in the past 7 days when at least one of the parents was with the adolescent when they ate their main meal

atmosphere were also significantly positively correlated with adequate fruit and vegetable intake.

\section{Qualitative factors that emerged}

Accessibility. Qualitative analysis led us to replace our initial deductive theme of food "availability" with "accessibility", as participants talked about choosing food that was in front of them or prepared for them: "I wouldn't get up to make a salad for me. If they make it, I eat it."

The interviews also reflected that respondents did not participate in food-related tasks and simply received food. References were made to the "nanny", "housemaid", or the mother as the individuals responsible for food preparation at home.

Food presentation. Appeal of food also emerged as an influencing factor on the students' food choices; they expressed willingness to try food that "looked good" such as packaged salads with special toppings or vegetables in familiar stews

Parental control. Some participants described their parents' support in the form of control over what they can or cannot eat. Some parents were said to prohibit certain foods. Students perceived the strategies their parents use to control their food intake as positive and helpful: "Since a young age (my parents) don't let us eat too much chocolate and stuff and I feel they do a good job", "My parents don't pay attention to what I eat but I feel that parents should...they should say eat this, don't eat too much of that".

Social and peer norms. Girls, in particular, described the eating habits of their school friends as a main influence on their food choices. They expressed sensitivity towards their friends' perception of what they ate: "my friends believe it would look funny (to eat an apple at school) so they discourage me to eat healthy food at school. I would feel more comfortable if everyone was eating it". Boys, on the other hand, did not seem affected by a certain context. They all made references to several environmental settings (besides school) where influential interactions with peers may occur including sports venues and during evening outings.

\section{Discussion}

Our results showed low rates of fruit and vegetable intake in Emirati adolescents, with significantly lower intake frequency among girls. These results are consistent with previous reports from the Gulf region. In Bahrain, only $25.3 \%$ and $26.3 \%$ of adolescents reported daily consumption of fruit and vegetables respectively. Girls were also less likely than boys to report adequate intake (21). In Saudi Arabia, more than 50\% of adolescents reported they "never" or "rarely" consumed fruit and vegetables (2). In 2013, a study among Kuwaiti adolescents similarly reported significantly lower intake of fruit and vegetables among girls than boys (22). In Western Europe and North America, low rates of fruit and vegetable intake are also common among adolescents, but they tend to be more pronounced among low-income families and certain ethnic groups (such as African Americans) (12,23). In contrast to our findings, girls in North America and Europe tend to report higher intake of fruit and vegetable than boys $(24,25)$. This said, our observed gender differences should to be interpreted in context. Our qualitative data suggest that the eating habits of boys may be influenced by a wider range of socioenvironmental factors than girls because they typically lead a more active and socially varied lifestyle, which may lead to higher energy needs and food intake.

Our analysis showed no correlation between skipping breakfast and adequate fruit and vegetable intake. This could be because, traditionally, fruit and vegetables are not eaten at breakfast in the region. Breakfast was the most commonly skipped meal in our study especially among girls. Similarly, in Bahrain, $62.8 \%$ of females versus $37.2 \%$ of males reported irregular breakfast consumption (21). Also, reports from Kuwait and Jeddah, Saudi Arabic showed that over half of the adolescent participants skipped the morning meal $(2,22)$.

Family meal frequency has been shown to positively influence the quality of adolescents' diet (26). Family lunches are a long-standing tradition in the Middle East (27). Culturally, this is different from European and North American societies, where dinner (the evening meal) is considered the main family meal. Yet our data indicate that the tension between lunch timing and modern 


\begin{tabular}{|c|c|c|c|c|}
\hline \multirow[t]{2}{*}{ Home environment variable } & \multicolumn{4}{|c|}{ Response categories $(n=620)$} \\
\hline & No. (\%) & No. (\%) & No. (\%) & No. $(\%)$ \\
\hline \multicolumn{5}{|l|}{ Parental support for healthy eating ${ }^{a}$} \\
\hline Rate the following statements & Not at all & A little bit & Somewhat & Very much \\
\hline My mother cares about eating healthy food & $19(3.1)$ & $95(15.3)$ & $173(27.9)$ & $324(52.3)$ \\
\hline My father cares about eating healthy food & $59(9.5)$ & $80(12.9)$ & $172(27.7)$ & $284(45.8)$ \\
\hline My mother encourages me to eat healthy food & $24(3.9)$ & $58(9.4)$ & $134(21.6)$ & $395(63.7)$ \\
\hline My father encourages me to eat healthy food & $59(9.5)$ & $95(15.3)$ & $134(21.6)$ & $305(49.2)$ \\
\hline \multicolumn{5}{|l|}{ Atmosphere at the family meal ${ }^{b}$} \\
\hline How strongly do you agree with the following statement? & $\begin{array}{l}\text { Strongly } \\
\text { disagree }\end{array}$ & Disagree & Agree & Strongly agree \\
\hline $\begin{array}{l}\text { In my family, mealtime is a time for talking with other family } \\
\text { members }\end{array}$ & $27(4.4)$ & $51(8.2)$ & $142(22.9)$ & $393(63.4)$ \\
\hline $\begin{array}{l}\text { In my family, meal time is about more than just getting food; } \\
\text { we talk with each other }\end{array}$ & $43(6.9)$ & $78(12.6)$ & $150(24.2)$ & $342(55.2)$ \\
\hline In my family, eating brings people together in an enjoyable way & $22(3.5)$ & $64(10.3)$ & $208(33.5)$ & $319(51.5)$ \\
\hline I enjoy eating meals with my family & $21(3.4)$ & $56(9.0)$ & $154(24.8)$ & $377(60.8)$ \\
\hline \multicolumn{5}{|l|}{ Importance of the family meal ${ }^{c}$} \\
\hline How strongly do you agree with the following statement? & $\begin{array}{l}\text { Strongly } \\
\text { disagree }\end{array}$ & Disagree & Agree & Strongly agree \\
\hline $\begin{array}{l}\text { In my family, it is important that the family eat at least one } \\
\text { meal a day together }\end{array}$ & $80(12.9)$ & $78(12.6)$ & $182(29.4)$ & $274(44.2)$ \\
\hline In my family we are expected to be home for the main meal & $33(5.3)$ & $78(12.6)$ & $205(33.1)$ & $291(46.9)$ \\
\hline $\begin{array}{l}\text { In my family, it is often difficult to find a time when family } \\
\text { members can sit down to eat a meal together }\end{array}$ & $84(13.5)$ & $160(25.8)$ & $139(22.4)$ & $227(36.6)$ \\
\hline $\begin{array}{l}\text { In my family, different schedules make it hard for us to eat } \\
\text { meals together }\end{array}$ & $155(25.0)$ & $217(35.0)$ & $116(18.7)$ & $125(20.2)$ \\
\hline
\end{tabular}

working hours might be affecting the family lunch and eating patterns of Emirati adolescents. More research is needed to assess the impact of this tension and possible means to preserve this family meal. Contrary to previous reports $(24,28)$, we did not find an association between family affluence and intake of fruit and vegetables. This could be due to the fact that the vast majority of students in this sample were from families of moderate to high affluence.

Fast food consumption among Emirati adolescents in our sample was as high as reports from neighbouring countries such as Saudi Arabia where $55.7 \%$ of adolescents eat outside the house (mainly in fast food restaurants) up to three times per week (2). In contrast with Kuwaiti adolescents, more girls $(30.5 \%)$ than boys $(27.2 \%)$ in our study reported eating fast food on 3 days or more in the past week (22).

Qualitative themes that emerged added important information that helped refine our interpretations. For example, the distinction we made between 'availability', and 'accessibility' has been previously highlighted in research on children's (rather than adolescents') dietary habits in the US, where accessibility was used to refer to "prepared fruits and vegetables within reach or in a visible place, in the fridge or on a table" (29). Adolescents in our study expressed a similar dependence on their social support system. This can be attributed to the strong cultural emphasis on children's dependence on family in this region, even during adolescence. Yet, in order to involve Emirati parents in future interventions, it is important to recognize potential challenges. For example, half of the parents in our study reportedly did not have higher education. These parents may lack the knowledge needed to guide the eating habits of their adolescent children (30).

Our results also indicated that subgroups of the adolescent population, defined by demographic and lifestyle factors, may require different intervention approaches. As an example, given the social restrictions on female lifestyle, schools become an important setting for socializing among Emirati girls. This may lead to a stronger influence of school social norms among females (30). On the other hand, social norms in boys' schools might be diluted, as they tend to have more opportunities to socialize outside school. It is also possible that girls are generally more responsive to peer influence than boys (31). We recommend further investigation of social and peer norms among Emirati adolescents.

Finally, our findings emphasize the need for supportive food environments in schools. In October of 


\begin{tabular}{|c|c|c|c|}
\hline \multirow[t]{2}{*}{ Variable } & \multicolumn{3}{|c|}{ Odds ratio ( $95 \%$ confidence interval) ${ }^{b}$} \\
\hline & Model 1 & Model 2 & Model 3 \\
\hline \multicolumn{4}{|l|}{ Dietary behaviour } \\
\hline Breakfast & $1.1(0.9-1.2)$ & $1.0(0.9-1.2)$ & $0.9(0.8-1.1)$ \\
\hline Lunch & $1.3(1.1-1.6)$ & $1.3(1.1-1.6)$ & $1.3(1.0-1.6)$ \\
\hline Dinner & $0.9(0.8-1.1)$ & $0.9(0.8-1.1)$ & $0.9(0.8-1.1)$ \\
\hline Soft drinks & $1.7(1.2-2.6)$ & $2.4(1.6-3.5)$ & $2.5(1.6-3.9)$ \\
\hline Snacking & $1.1(0.9-1.3)$ & $1.2(0.96-1.4)$ & $1.3(1.0-1.6)$ \\
\hline Fast-food meals & $0.8(0.6-1.1)$ & $0.8(0.6-1.1)$ & $0.9(0.7-1.3)$ \\
\hline Sex (male) & - & $1.6(1.1-2.4)$ & $1.7(1.1-2.7)$ \\
\hline Age & - & $1.1(0.9-1.3)$ & $1.2(0.9-1.4)$ \\
\hline \multicolumn{4}{|l|}{ Home environment } \\
\hline Family affluence & - & - & $1.0(0.8-1.4)$ \\
\hline Parental support for healthy eating & - & - & $1.1(0.99-1.2)$ \\
\hline Family meal frequency & - & - & $0.9(0.7-1.2)$ \\
\hline Family meal priority & - & - & $0.9(0.8-1.00)$ \\
\hline Family meal atmosphere & - & - & $1.1(0.99-1.2)$ \\
\hline Home availability of fruits and vegetables & - & - & $0.97(0.7-1.4)$ \\
\hline
\end{tabular}

${ }^{a}$ Eating fruit and vegetables 5 or more times a day.

${ }^{b}$ Generalized linear mixed model - model 1: unadjusted model [AIC (Akaike information criterion) $\left.=547.2\right]$; model 2: adjusted for age and sex (AIC =667.4); model 3: adjusted for dietary behaviour, age, sex

2012, after finalizing the data collection for this study, and independent of our research project, the Ministry of Education of the UAE made a significant move towards improving the quality of school food across the country. A 15-page guide for school caterers was issued (32). The guide reportedly bans the selling of fried potatoes, crisps, ice creams and chocolate in schools. Such initiatives could be re-examined to assess their effect on eating habits and attitudes of adolescents. Future school-based interventions could use creative ways to introduce fruits and vegetables, such as fresh cocktails and attractive salads. Another idea is to install a salad bar in the school cafeteria, offering a colourful selection of fresh products and allowing students to build their own plates. Salad bars have been shown to entice adolescents to try new vegetables and fruits $(33,34)$.

\section{Limitations}

The cross-sectional design of this study and exclusion of Emirati students attending private high schools where Arabic is taught as a second language may limit the generalizability of the results. However, we argue that language is an important component of the cultural homogeneity in our target population for future interventions. We did not formally validate the adapted questionnaire used in this study; however, it was formally back translated to Arabic and was successfully piloted for face and construct validity. Finally, the qualitative sample size was partly determined by thematic saturation. True data saturation is difficult to achieve; however we argue that the purposeful sampling within the larger sample and the homogeneity of the qualitative sample helped achieve the supplemental purpose of our qualitative interviews and enhance thematic saturation.

\section{Conclusion}

Despite the similarities between eating behaviours of Emirati adolescents and those reported in Western Europe and North America, there are unique socioenvironmental and lifestyle influences that affect male versus female Emirati adolescents differently. Future interventions may benefit from gender-specific strategies as well as creative school-based programmes.

Funding: None.

Competing interests: None declared 
Six questions assessed self-reported intake of fruit (two questions for fruits and 100\% fruit juice) and vegetables (four questions for green salad, potatoes-other than french-fries, carrots, and other vegetables) in the past 7 days. The response scale ranged from $0=$ none in the past 7 days to $6=4$ or more times per day. The scale was later dichotomized into 0 $=$ does not meet recommended daily intake and $1=$ meets recommended daily intake for fruit and vegetables combined. The cut-off score was " $\geq 5$ portions per day" for fruit and vegetables combined (ftp://ftp.cdc.gov/pub/data/yrbs/2009/yrbs_2009_national_user_ guide.pdf).

Meal patterns

Frequency of intake of main meals was assessed with the question "During the past week, how many days did you eat breakfast/lunch/dinner?" Response categories were "never, 1-2 days, 3-4 days, 5-6 days and every day"

Fast food

Frequency of fast food intake was assessed with the question "In the past week, how often did you eat something from a fast food restaurant (like McDonalds, Burger King, Hardees, etc.)?" Response categories were "never, 1-2 times and 3 times or more"

Snacking

Frequency of snacking was assessed with the question "How many times did you snack (eat between meals) yesterday?" Range: $0=$ none; $4=$ more than 5 times; recoded into $0=$ none; 3 = 4 times or more

Soft drinks

Soft drinks consumption was measured with the question "During the past 7 days, how many times did you drink a can, bottle, or glass of soda or pop, such as Coke, Pepsi, or Sprite?" Response categories were "none, less than once a day, at least once a day".

Family affluence

We calculated a composite score for family affluence scale by summing the responses to 4 items including number of cars owned by family, having own bedroom, family holidays in the past year and number of family computers. Then, we recoded the sum into a 3-point ordinal scale (low, medium and high family affluence) (Richter M, Moor I, van Lenthe FJ. Explaining socioeconomic differences in adolescent self-rated health: the contribution of material, psychosocial and behavioural factors. J Epidemiol Community Health. 2012 Aug;66(8):691-7. https://doi.org/10.1136/jech.2010.125500 PMID:21543387).

Family meals Frequency of family meals was assessed with the question "During the past 7 days, how many times did all, or most, of your family living in your house, eat a meal together?" Response categories were "1-2 times, 3-6 times, and 7 or more times"

Parental presence at meal "On how many of the past 7 days was at least one of your parents in the room with you when you ate your main meal?" Responses ranged from "never" to "every day"

Priority of family meals

Five statements, rated on a 4-point Likert-scale: "In my family, it is important that the family eat at least one meal a day together", "In my family we are expected to be home for dinner", "I am often just too busy to eat dinner with my family", "In my family, different schedules make it make it hard to eat meals together on a regular basis", "In my family, it is often difficult to find a time when family members can sit down to a meal together". Coding reversed for the last 3 items, range: $0=$ strongly disagree; $3=$ strongly agree

Parental support for healthyeating

Four statements, rated on a 4-point Likert scale: "My mother cares about eating healthy food", "My mother encourages me to eat healthy foods". Same questions for the father. Range: 0 = not at all; 3 = very much

Atmosphere at family meal Four statements, rated on a 4-point Likert scale : "I enjoy eating meals with my family", "In my family, eating brings people together in an enjoyable way", "In my family, mealtime is a time for talking with other family members", "In my family, dinner time is about more than just getting food; we talk with each other". Range: $0=$ strongly disagree; 3 = strongly agree

Availability of fruits and vegetables at home/school

Two statements, rated on a 4-point Likert scale on availability of fruits and vegetables at home. One statement for availability of fruits and vegetables at school. Range $0=$ never; 3 = always

Availability of unhealthy snacks
Six statements, rated on a 4-point Likert scale on availability of chips and salty snacks; chocolate and candy, and soft drinks at home and school. Range: $0=$ never; $3=$ always 


\section{L'apport en fruits et légumes chez les adolescents émiratis : une étude à méthodologie mixte}

\section{Résumé}

Contexte : Les adolescents des Émirats arabes unis doivent être encouragés à adopter une alimentation saine. Afin de mettre en place des interventions efficaces à cet effet, il faut tout d'abord bien comprendre les comportements alimentaires des adolescents.

Objectif : La présente étude avait pour objectif de décrire les comportements alimentaires des adolescents à Dubaï ainsi que les différents facteurs liés à leur apport en fruits et légumes.

Méthodes: Il s'agissait d'une étude séquentielle à visée explicative qui s'appuyait sur une approche méthodologique mixte. Dix des 34 lycées arabes de Dubaï ont été choisis au hasard et on y a recruté des élèves du secondaire (15-18 ans). Les données recueillies concernaient l'apport en fruits et légumes autodéclaré par les élèves, les comportements alimentaires, la disponibilité de la nourriture et les variables sociodémographiques. Lors de la phase qualitative, 14 élèves ont été questionnés au regard de leur comportement alimentaire.

Résultats : Au total, 620 élèves ont été inclus, dont $57 \%$ de garçons, et la plupart ont déclaré un niveau d'aisance familiale moyen à aisé. Seuls $28 \%$ des participants atteignaient le niveau recommandé en matière d'apport quotidien en fruits et légumes, dont une part significativement plus élevée de garçons que de filles $(p<0,01)$. Le repas le plus fréquemment consommé était le déjeuner, le petit-déjeuner était souvent négligé et le taux de consommation de fast-food et de boissons gazeuses était élevé. Un bon apport en fruits et légumes a été corrélé de façon positive avec une prise de déjeuner plus fréquente, une appartenance au sexe masculin, un soutien parental en faveur d'une alimentation saine et une perception favorable des repas de famille.

Conclusion : Des différences significatives sur le plan des habitudes alimentaires ont été notées entre les adolescents et les adolescentes émiratis. Les horaires de travail actuels constituent une menace pour le traditionnel déjeuner familial. Le contexte social étant propre à chaque sexe, il pourrait s'avérer nécessaire de cibler les interventions afin d'optimiser les résultats au sein de chaque groupe.

$$
\begin{aligned}
& \text { تناول الفاكهة والخضر اوات لدى المر اهقين في الإمارات العربية المتحدة: دراسة باستخدام طرق مختلطة } \\
& \text { نورا مكانسي، باول أليسون، منال عوض، كريستوف بيدوس } \\
& \text { الخلاصة } \\
& \text { الخلفية: هناك حاجة إلى تدخلات لتعزيز الأكل الصحي لدى الماتر اهنقين في الإمارات العربية المتحدة. ومن أجل تصميم التدخلات الفعالة، لا بدّ }
\end{aligned}
$$

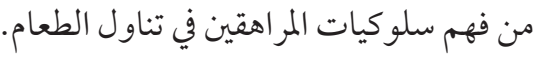

$$
\begin{aligned}
& \text { الأهداف: هدفت هذه الدراسة إلى وصف سلوكيات المر اهقين في تناول الطعام في دبي والعوامل المرتبطة بتناول الفو اكه والخضراوات. }
\end{aligned}
$$

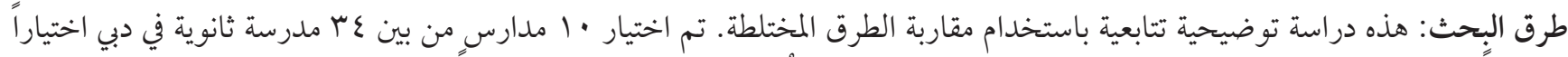

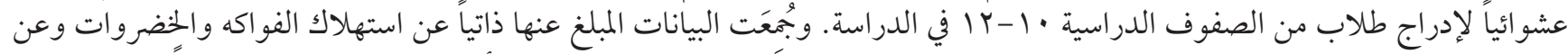

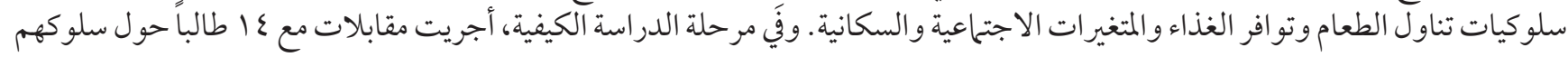

$$
\begin{aligned}
& \text { في تناول الطعام. }
\end{aligned}
$$

\section{References}

1. Al-Hazzaa HM, Musaiger AO; ATLS Research Group. Arab Teens Lifestyle Study (ATLS): objectives, design, methodology and implications. Diabetes Metab Syndr Obes. 2011;4:417-26. https://doi.org/10.2147/DMSO.S26676 PMID:22253540

2. Washi SA, Ageib MB. Poor diet quality and food habits are related to impaired nutritional status in 13-to 18-year-old adolescents 
in Jeddah. Nutr Res. 2010 Aug;30(8):527-34. https://doi.org/10.1016/j.nutres.2010.07.002 PMID:20851306

3. Moreno LA, Rodríguez G, Fleta J, Bueno-Lozano M, Lázaro A, Bueno G. Trends of dietary habits in adolescents. Crit Rev Food Sci Nutr. 2010 Feb;50(2):106-12. https://doi.org/10.1080/10408390903467480 PMID:20112152

4. Szajewska H, Ruszczyński M. Systematic review demonstrating that breakfast consumption influences body weight outcomes in children and adolescents in Europe. Crit Rev Food Sci Nutr. 2010 Feb;50(2):113-9. https://doi.org/10.1080/10408390903467514 PMID:20112153

5. Ng SW, Zaghloul S, Ali H, Harrison G, Yeatts K, El Sadig M, et al. Nutrition transition in the United Arab Emirates. Eur J Clin Nutr. 2011 Dec;65(12):1328-37. https://doi.org/10.1038/ejcn.2011.135 PMID:21772317

6. bin Zaal AA, Musaiger AO, D'Souza R. Dietary habits associated with obesity among adolescents in Dubai, United Arab Emirates. Nutr Hosp. 2009 Jul-Aug;24(4):437-44. PMID:19721923

7. Musaiger A, Bener A, Bin Ishaq S, Al-Hosani H. Cardiovascular disease in the UAE: an overview. Emirates J Food Agric. 1994;6(1):86-99.

8. CVD time bomb set to explode in Gulf region in 10-15 years. ESC: European Society of Cardiology. Press release, 13 February 2013 (https://www.escardio.org/The-ESC/Press-Office/Press-releases/CVD-time-bomb-set-to-explode-in-Gulf-region-in-10-15-years, accessed 16 April 2018).

9. Srinath Reddy K, Katan MB. Diet, nutrition and the prevention of hypertension and cardiovascular diseases. Public Health Nutr. 2004 Feb;7 1A:167-86. PMID:14972059

10. Statistics reports - education. Dubai: Dubai Statistics Center; 2010 (https://www.dsc.gov.ae/en-us/Themes/Pages/Education. aspx?Theme=37, accessed 16 April 2018).

11. Al-Hazzaa HM, Abahussain NA, Al-Sobayel HI, Qahwaji DM, Musaiger AO. Physical activity, sedentary behaviors and dietary habits among Saudi adolescents relative to age, gender and region. Int J Behav Nutr Phys Act. 2011 12 21;8(1):140. https://doi. org/10.1186/1479-5868-8-140 PMID:22188825

12. Neumark-Sztainer D, Wall M, Perry C, Story M. Correlates of fruit and vegetable intake among adolescents. Findings from Project EAT. Prev Med. 2003 Sep;37(3):198-208. https://doi.org/10.1016/Soo91-7435(03)oo114-2 PMID:12914825

13. Eng J. Sample size estimation: how many individuals should be studied? Radiology. 2003 May;227(2):309-13. https://doi. org/10.1148/radiol.2272012051 PMID:12732691

14. University of Minnesota. Project EAT. Epidemiology and community health research; updated 2017 (http://www.sphresearch. umn.edu/epi/project-eat/, accessed May 2017).

15. Eaton DK, Kann L, Kinchen S, Shanklin S, Flint KH, Hawkins J, et al. Youth risk behavior surveillance-United States, 2011. MMWR Surveill Summ. 2012 Jun 8;61(4):1-162. PMID:22673000.

16. Beaton DE, Bombardier C, Guillemin F, Ferraz MB. Guidelines for the process of cross-cultural adaptation of self-report measures. Spine. 2000 Dec 15;25(24):3186-91. https://doi.org/10.1097/00007632-200012150-00014 PMID:11124735

17. Heck RH, Thomas SL, Tabata LN. Multilevel modeling of categorical outcomes using IBM SPSS. New York (NY): Taylor and Francis; 2012.

18. Youth Risk Behavior Survey. Data users manual. Atlanta (GA): US Centers for Disease Control and Prevention; 2009 (ftp://ftp.cdc. gov/pub/data/yrbs/2009/yrbs_2009_national_user_guide.pdf, accessed 21 March 2018).

19. Morse JM. Approaches to qualitative-quantitative methodological triangulation. Nurs Res. 1991 Mar-Apr;40(2):120-3. PMID:2003072

20. Mayring P. Qualitative content analysis. Forum: Qualitative Social Research. June 2000;1(2). Art. 20(http://www.qualitative-research.net/index.php/fqs/article/viewArticle/1089/2385, accessed 21 March 2018).

21. Musaiger A, Bader Z, Al-Roomi K, D'Souza R. Dietary and lifestyle habits amongst adolescents in Bahrain. Food Nutr Res. 2011 Jan 1;55(1). https://doi.org/10.3402/fnr.v55io.7122 PMID:21912533.

22. Allafi A, Al-Haifi AR, Al-Fayez MA, Al-Athari BI, Al-Ajmi FA, Al-Hazzaa HM, et al. Physical activity, sedentary behaviours and dietary habits among Kuwaiti adolescents: gender differences. Public Health Nutr. 2014 Sep;17(9):2045-52. https://doi.org/10.1017/ S1368980013002218 PMID:23987909

23. Wind M, de Bourdeaudhuij I, te Velde SJ, Sandvik C, Due P, Klepp K-I, et al. Correlates of fruit and vegetable consumption among 11-year-old Belgian-Flemish and Dutch schoolchildren. J Nutr Educ Behav. 2006 Jul-Aug;38(4):211-21. https://doi.org/10.1016/j. jneb.2006.02.011 PMID:16785090

24. Rasmussen M, Krølner R, Klepp KI, Lytle L, Brug J, Bere E, et al. Determinants of fruit and vegetable consumption among children and adolescents: a review of the literature. Part I: Quantitative studies. Int J Behav Nutr Phys Act. 2006 08 11;3(1):22. https:// doi.org/10.1186/1479-5868-3-22 PMID:16904006

25. Vereecken CA, De Henauw S, Maes L. Adolescents' food habits: results of the Health Behaviour in School-aged Children survey. Br J Nutr. 2005 Sep;94(3):423-31. https://doi.org/10.1079/BJN20051513 PMID:16176614

26. Larson NI, Neumark-Sztainer D, Hannan PJ, Story M. Family meals during adolescence are associated with higher diet quality and healthful meal patterns during young adulthood. J Am Diet Assoc. 2007 Sep;107(9):1502-10. https://doi.org/10.1016/j. jada.2007.06.012 PMID:17761227 
27. Heine P. Food culture in the Near East, Middle East, and North Africa. Westport (CT): Greenwood Publishing Group; 2004.

28. Nabhani-Zeidan M, Naja F, Nasreddine L. Dietary intake and nutrition-related knowledge in a sample of Lebanese adolescents of contrasting socioeconomic status. Food Nutr Bull. 2011 Jun;32(2):75-83. https://doi.org/10.1177/156482651103200201 PMID:22164969

29. Hearn MD, Baranowski T, Baranowski J, Doyle C, Smith M, Lin LS, et al. Environmental influences on dietary behavior among children: availability and accessibility of fruits and vegetables enable consumption. J Health Educ. 1998;29(1):26-32. https://doi.or g/10.1080/10556699.1998.10603294

30. Russell A, Coughlin C, El Walily M, Al Amri M. Youth in the United Arab Emirates: Perceptions of problems and needs for a successful transition to adulthood. Int J Adolesc Youth. 2005;12(3):189-212. https://doi.org/10.1080/02673843.2005.9747952

31. Salvy S-J, Elmo A, Nitecki LA, Kluczynski MA, Roemmich JN. Influence of parents and friends on children's and adolescents' food intake and food selection. Am J Clin Nutr. 2011 Jan;93(1):87-92. https://doi.org/10.3945/ajcn.110.002097 PMID:21048059

32. Ahmed A. Junk food taken off the menu in UAE schools. The National. 10 October 2012 (https://www.thenational.ae/uae/education/junk-food-taken-off-the-menu-in-uae-schools-1.412231, accessed 21 March 2018).

33. Harris DM, Seymour J, Grummer-Strawn L, Cooper A, Collins B, DiSogra L, et al. Let's move salad bars to schools: a public-private partnership to increase student fruit and vegetable consumption. Child Obes. 2012 Aug;8(4):294-7. https://doi.org/10.1089/ chi.2012.0094 PMID:22867066

34. Slusser WM, Cumberland WG, Browdy BL, Lange L, Neumann C. A school salad bar increases frequency of fruit and vegetable consumption among children living in low-income households. Public Health Nutr. 2007 Dec;10(12):1490-6. https://doi. org/10.1017/S1368980007000444 PMID:1761075 